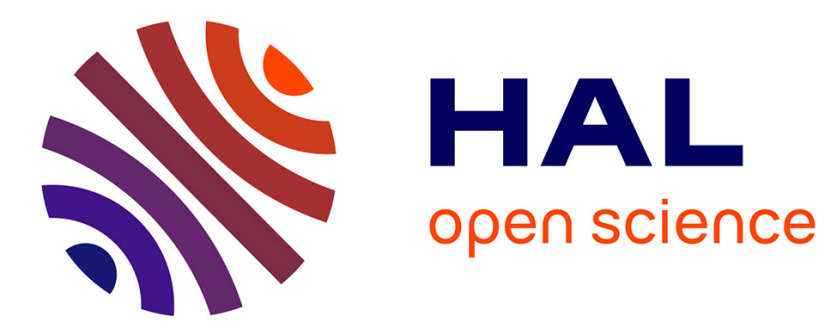

\title{
Chemical tunability of europium emission in phosphate glasses
}

\author{
Maria Rita Cicconi, Alexander Veber, Dominique De Ligny, Jean Rocherullé, \\ Ronan Lebullenger, Franck Tessier
}

\section{- To cite this version:}

Maria Rita Cicconi, Alexander Veber, Dominique De Ligny, Jean Rocherullé, Ronan Lebullenger, et al. Chemical tunability of europium emission in phosphate glasses. Journal of Luminescence, 2017, 183, pp.53-61. 10.1016/j.jlumin.2016.11.019 . hal-01475462

HAL Id: hal-01475462

https://hal-univ-rennes1.archives-ouvertes.fr/hal-01475462

Submitted on 4 May 2017

HAL is a multi-disciplinary open access archive for the deposit and dissemination of scientific research documents, whether they are published or not. The documents may come from teaching and research institutions in France or abroad, or from public or private research centers.
L'archive ouverte pluridisciplinaire HAL, est destinée au dépôt et à la diffusion de documents scientifiques de niveau recherche, publiés ou non, émanant des établissements d'enseignement et de recherche français ou étrangers, des laboratoires publics ou privés. 


\section{Author's Accepted Manuscript}

Chemical tunability of europium emission in phosphate glasses

Maria Rita Cicconi, Alexander Veber, Dominique de Ligny, Jean Rocherullé, Ronan Lebullenger, Franck Tessier

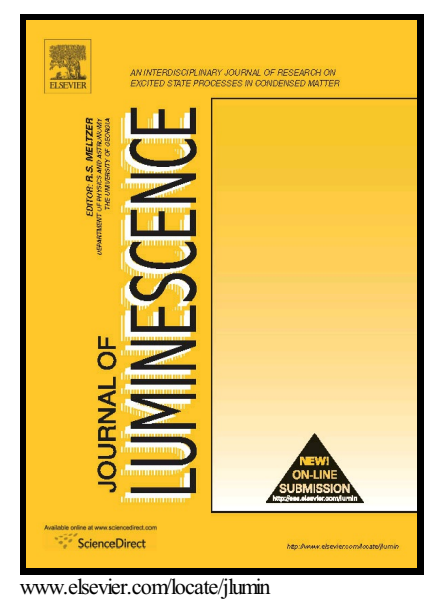

PII: $\quad$ S0022-2313(16)30043-6

DOI: $\quad$ http://dx.doi.org/10.1016/j.jlumin.2016.11.019

Reference: LUMIN14357

To appear in: Journal of Luminescence

Received date: 11 January 2016

Revised date: 30 August 2016

Accepted date: 5 November 2016

Cite this article as: Maria Rita Cicconi, Alexander Veber, Dominique de Ligny, Jean Rocherullé, Ronan Lebullenger and Franck Tessier, Chemical tunability o europium emission in phosphate glasses, Journal of Luminescence http://dx.doi.org/10.1016/j.jlumin.2016.11.019

This is a PDF file of an unedited manuscript that has been accepted fo publication. As a service to our customers we are providing this early version o the manuscript. The manuscript will undergo copyediting, typesetting, an review of the resulting galley proof before it is published in its final citable form Please note that during the production process errors may be discovered whic could affect the content, and all legal disclaimers that apply to the journal pertain 


\title{
Chemical tunability of europium emission in phosphate glasses
}

Maria Rita Cicconi ${ }^{*}$, Alexander Veber ${ }^{1,2}$, Dominique de Ligny ${ }^{1}$, Jean Rocherulle $^{3}$, Ronan Lebullenger $^{3}$, Franck Tessier ${ }^{3}$

${ }^{1}$ Department Werkstoffwissenschaften, Lehrstuhl für Glas und Keramik, Universität ErlangenNürnberg. Martensstrasse 5, D-91058 Erlangen, Germany

${ }^{2}$ Energy campus Nürnberg (EnCN), D-90429 Nürnberg, Germany

${ }^{3}$ Institut des Sciences Chimiques de Rennes (UMR CNRS 6226), équipe "Verres et Céramiques", Université de Rennes 1, F-35042 Rennes Cedex, France

*Corresponding author. Department Werkstoffwissenschaften, Lehrstuhl für Glas und Keramik, Universität Erlangen-Nürnberg. Martensstrasse 5, D-91058 Erlangen phone: +49 91318527567 maria.rita.cicconi@fau.de

\begin{abstract}
In this study the correlation between bulk chemistry and optical properties for a set of Eu-bearing phosphate glasses, containing different alkali elements, synthetized in air and under $\mathrm{NH}_{3}$ flux, was investigated. The chemistry of the glass strongly influences several properties and the effects of bulk chemistry and synthesis conditions on glass structure and on thermal and optical properties are discussed.
\end{abstract}

In alkali-phosphate glasses studied by absorption and photoluminescence spectroscopy we verified that $\mathrm{Eu}^{2+}$ emission band shifts toward higher wavelengths by substituting the alkali cation $(\mathrm{Na}<\mathrm{NaK}<\mathrm{K})$. Nitridation enhances the glass stability and the synthesis approach carried out enhances the presence of reduced Eu species, producing modifications both on the position and on the broadening of $\mathrm{Eu}^{2+}$ luminescence band.

The glass emission tunability is extremely related to the bulk composition and it is possible to adjust the chemistry in order to get the desired lighting in phosphate glasses.

Keywords: Nitridation Luminescence Phosphorus Optical basicity 


\section{Introduction}

Among the Rare Earth Elements (REE), europium and cerium are the only two elements presenting two stable oxidation states rather than only the trivalent one. Their luminescent properties are known to be very sensitive to the surrounding structural environment i.e. [1,2]. Previous studies on borophosphate, boroaluminate, and boroaluminosilicate glasses [3-5] shown that the optical basicity of the glasses affects the Eu oxidation state (higher the optical basicity, higher is the amount of oxidized species). In turn, it is also possible to correlate the $\mathrm{NBO} / \mathrm{T}$ parameter (non-bridging oxygen over tetrahedra) to the Eu redox ratio, as described for simplified and multicomponent silicate glasses [6-8].

Rare-earth-doped glasses are key materials for optical technology due to the luminescent properties of $4 \mathrm{f}^{\mathrm{n}}$ ions, thus REE are the most widely used phosphors in devices for lighting and displays, and also their use is economically and technologically important for applications in many fields (e.g. phosphors and LEDs). Especially the tunability of Eu allows designing versatile phosphorus. Unfortunately, REE in nature are relatively rare since they are mainly present in trace amounts in minerals like carbonates, aluminosilicates and titanosilicates. Only phosphate minerals easily incorporate large amount of REE [9]. Recently, particular attention is being paid to the possibility of improving the recycling process of REE-bearing compounds (from extraction, to reuse) and to a more efficient use of REE compounds [10].

Among phosphate materials, glasses are of great technological interest due to specific thermal properties like low thermal glass transition and dilatometric softening temperatures or high thermal expansion coefficients, which make them ideal as low-temperature sealing glasses [11]. However they suffer from a severe drawback which is often associated, i.e. their low chemical durability. Nevertheless, the nitridation ability of these glasses under ammonia is a suitable way to improve their chemical resistance [12]. During nitridation, both bridging 
(BO) and non-bridging oxygens of $\mathrm{PO}_{4}$ are substituted by nitrogen ions, thus forming two new structural units, $\mathrm{PO}_{3} \mathrm{~N}$ and $\mathrm{PO}_{2} \mathrm{~N}_{2}$ tetrahedra, where nitrogen atoms are either 2-fold $\left(\mathrm{N}_{\mathrm{d}}\right.$ species) or 3-fold coordinated $\left(\mathrm{N}_{\mathrm{t}}\right.$ species) with phosphorus atoms [13]. Careful synthetic control of the $\mathrm{O} / \mathrm{N}$ ratio is thus important for tuning the materials properties of the final oxynitrides, especially when mixed oxidation states are present. Oxide and nitride may substitute for each other in many crystalline structures if a compensating redox mechanism involving cations is available [14].

Ammonolysis is a technique which presents many advantages for the synthesis of oxynitride phosphors. A typical set-up for ammonolysis only involves a tubular furnace with flowing ammonia gas. Furthermore, ammonolysis shows a decisive advantage for phosphor synthesis: ammonia gas is both reduced and nitrided. Indeed, $\mathrm{NH}_{3}$ is totally dissociated at the reaction temperature (see Appendix A), and since nitrogen and hydrogen produced by the decomposition of ammonia are in nascent state, they are very reactive in terms of reductionnitridation abilities. As a consequence, nitridation is expected to lead both significant changes in $\mathrm{NBO} / \mathrm{BO}$ and $\mathrm{Eu}^{3+} / \mathrm{Eu}^{2+}$ redox ratio.

Europium characteristic emissions have been widely investigated in many systems, and $\mathrm{Eu}^{3+}$-bearing materials are promising red-emitting solid-state materials. Indeed, most of these studies were focused on the understanding of the structural environment of $\mathrm{Eu}^{3+}$ ions, due to the narrow and almost monochromatic ${ }^{5} \mathrm{D}_{0^{-}}>{ }^{7} \mathrm{~F}_{2}$ transition at $\sim 613 \mathrm{~nm}$ and to its long lifetimes [e.g. 2,15,16]. Nevertheless, in the past decades many studies tried to influence the valence states of europium ion in solid-state materials, mainly in borate, boro-silicate and boro-phosphate glasses, or silicate and aluminosilicate glasses [3-5 and references therein].

In this study we investigated europium in a set of metaphosphate glasses in order to verify the effect of bulk chemistry and nitridation on both Eu redox state and optical properties. 
The choice of a phosphate host composition as base composition was also guided by environmental considerations i) production of phosphate glasses requires lower synthesis temperatures, and therefore less energy, with respect to silicate glasses or ceramics; ii) REE could be reconcentrated by crystallization of phosphate phases after the use of the device in order to form congruent minerals and in turn, to recover REE; iii) crystallized REE species could be extracted by using the procedures already established for phosphate minerals in Ore deposits. REE-based device will be then a real environmental friendly product where the total life cycle would have been optimized.

Being the first part of a larger project on the development of "green" Eu-based phosphors, this work report how different phosphate glasses act on Eu redox and luminescence behaviour.

\section{Experimental methods}

Europium phosphate glasses were prepared by mixing dry europium oxide $(1 \mathrm{wt} \%$ $\left.\mathrm{Eu}_{2} \mathrm{O}_{3}\right)$ and phosphate salts $\left(\mathrm{NaPO}_{3}, \mathrm{Ca}\left(\mathrm{PO}_{3}\right)_{2}, \mathrm{KPO}_{3}\right)$ in stoichiometric proportions. The mixture was melted in a quartz crucible at $900{ }^{\circ} \mathrm{C}$ for 30 minutes and glasses were obtained by pouring the melt into preheated brass molds. Annealing process was carried out at 325$350^{\circ} \mathrm{C}$ for 30 minutes and then the material was cooled down to room temperature in 3 hours. Aliquots on the order of $1 \mathrm{~g}$ of each glass were melted at $750^{\circ} \mathrm{C}$ in a glassy carbon crucible under $\mathrm{NH}_{3}$-flux for 19 hours (heating rate $10^{\circ} \mathrm{C} / \mathrm{min}$ ). This temperature avoids the phosphorous reduction, and the low viscosity of the melt at this temperature determines the nitridation rate, which is a diffusion controlled phenomenon, and also affects the maximum nitrogen content in the glass matrix.

The batch compositions of the investigated glasses are reported in Table 1. All the samples synthesized in air appeared highly transparent and were checked for homogeneity and absence of crystals by XRD, optical microscopy and Raman. Small pieces of these glass 
samples were polished and used for optical / measurements. N-treated samples were transparent, even if they present bubbles. Only the K sample after nitridation shown some crystallization on one side of the crucible, the non-crystallized part was used after checking that its chemical composition was not modified from the nominal one. Nitrogen analysis was carried out in a $\mathrm{N}_{2} / \mathrm{O}_{2}$ analyzer LECO. The glass characteristic temperatures, i.e. glass transition, onset crystallization peak and melting, of both Eu-bearing and undoped samples were measured from differential scanning calorimetry (DSC, NETZSCH DSC 404F1) at a constant heating rate of $10^{\circ} \mathrm{C} \min ^{-1}$. In all cases no aging of the samples was observed demonstrating a good behavior in regard of atmospheric water.

Analyses of optical emission and excitation behavior (PL) were performed with a spectrofluorometer equipped with double monochromators (Czerny-Turner) in excitation and emission (Fluorolog3, Horiba Jobin Yvon; used spectral resolution $\sim 0.5 \mathrm{~nm}$ ), using a $450 \mathrm{~W}$ Xe-lamp as excitation source. Absorption spectra were measured using an UV/VIS spectrometer (Lambda 950, Perkin Elmer).

\section{Results}

\section{1 - Thermal properties}

Table 1 shows different properties of the studied glass compositions. After the same heat treatment, the maximum nitrogen content is much lower for the Na-bearing glass. When potassium is substituted for sodium, or whether potassium is the only alkali element, the nitrogen content increases drastically.

Considering undoped glasses as references, it is obvious that both europium and nitrogen greatly enhance the glass transition temperature and the onset temperature of crystallization. On the contrary, the melting temperatures are decreasing. In Figure 1 are reported the DSC curves for the three metaphosphate glasses doped with $1 \mathrm{wt} \% \mathrm{Eu}_{2} \mathrm{O}_{3}$ where it can be seen a clear variation of the glass transition $(\mathrm{Tg})$, the melting $(\mathrm{Tm})$ and the 
crystallization temperature (Tx) depending on the glass chemistry. In particular, the mixed alkali effect is evidenced on Tg values (inset in Fig. 1), as for the undoped glasses. However, when nitrogen is introduced in the glass network, the mixed alkali effect disappears (Table 1). The Hrubÿ parameter [17] is also largely increased when both europium and nitrogen are added to the based oxide glasses, providing an increase of the glass stability. The optical basicity, which has been calculated for the oxide glass compositions, shows an increase of 8.5\% when substituting potassium for sodium.

\section{2 - Absorption measurements}

Absorption spectra of phosphate undoped glasses, Eu-doped glasses synthetized in air, and nitrided glasses are reported in Figure 2. In each spectrum the most intense peak is located at $\sim 393 \mathrm{~nm}$ and it is associated to the $\mathrm{Eu}^{3+}$ transition ${ }^{7} \mathrm{~F}_{0^{-}}{ }^{5} \mathrm{~L}_{6}$.

Undoped phosphate glasses, used as references, indicate the presence of some impurities (increasing background) in the UV region. However, they do not present any band in the VIS region that can interfere with Eu bands (black lines in Fig. 2). The Eu-bearing glasses synthetised in air (red lines in Fig. 2) present sharp bands associated to the excited states from the ground states of $\mathrm{Eu}^{3+}$, and a broad band around $325 \mathrm{~nm}$ associated with the presence of $\mathrm{Eu}^{2+}$. This band somewhat shifts at higher wavelengths depending on the alkali cation present. After nitridation (blue lines in Fig. 2) the intensity of the $\mathrm{Eu}^{2+}$ band markedly increases for all the samples, along with a decrease (up to 20\%) of the $\mathrm{Eu}^{3+}$ band intensities.

\section{3 - PL of glasses synthetized in air}

Photoluminescence (PL) measurements confirmed the presence of both Eu species. Figure 3a (upper panels) shows the normalised PL and excitation spectra for alkali-doped metaphosphate glasses, respectively measured under excitation at $392 \mathrm{~nm}$ and emission at 613 nm. All the sharp peaks are associated to $\mathrm{Eu}^{3+}$ and the main emission peaks (Fig. 3a) are associated to the electronic transitions ${ }^{5} \mathrm{D}_{0^{-}}>{ }^{7} \mathrm{~F}_{1}$ at $592 \mathrm{~nm},{ }^{5} \mathrm{D}_{0^{-}}>{ }^{7} \mathrm{~F}_{2}$ at $613 \mathrm{~nm}$ and ${ }^{5} \mathrm{D}_{0^{-}}>{ }^{7} \mathrm{~F}_{4}$ 
at $700 \mathrm{~nm}$. The spectra for the different phosphate glasses do not significantly change, and only slightly differences in the relative intensities of the peaks can be observed.

Figure $3 \mathrm{~b}$ (lower panels) shows the optical properties of $\mathrm{Eu}^{2+}$ in the investigated glasses. Emissions and excitation spectra were measured respectively under $330 \mathrm{~nm}$ excitation and at the fluorescence maximum (marked with vertical arrows in Fig. 3b). The excitation wavelength used allowed suppressing most of $\mathrm{Eu}^{3+}$ luminescence, even if $\mathrm{Eu}^{3+}$ bands are still visible in the emission spectra in the range above $570 \mathrm{~nm}$. The broad bands from 370 to 570 $\mathrm{nm}$ are associated to $5 d-4 f$ electronic transition $\left(4 f^{6} 5 \mathrm{~d}->4 \mathrm{f}^{7}\right)$ of $\mathrm{Eu}^{2+}$ ions. In contrast to $\mathrm{Eu}^{3+}$ bands, there is a strong shift toward higher wavelength $(\sim 50 \mathrm{~nm})$ by substituting the alkali cation (in the order $\mathrm{Na}<\mathrm{NaK}<\mathrm{K}$ ). The shift of $\mathrm{Eu}^{2+}$ emission bands is combined with a shift in the corresponding excitation bands (Fig. $3 b$ and Table 2).

\section{4 - PL of N-treated alkali phosphate glasses}

All the samples were treated under $\mathrm{NH}_{3}$-flux, in a glassy carbon crucible at $750^{\circ} \mathrm{C}$, and the resulting glasses still present both $\mathrm{Eu}^{3+}$ and $\mathrm{Eu}^{2+}$ emission bands. On the other hand, $\mathrm{N}-$ treated glasses present higher intensities of the $\mathrm{Eu}^{2+}$ emission lines, along with a decrease of the relative intensities of the $\mathrm{Eu}^{3+}$ bands (Fig. 4). Furthermore, there is a noticeable influence on the $\mathrm{Eu}^{2+}$ luminescence bands, both in terms of position of the maxima and as broadening (Fig. 4). Especially sample NaKPEuN that beside the clear shift toward higher wavelengths $(\sim 10 \mathrm{~nm})$ has a marked broadening $(>10 \%)($ Fig. 4 and Table 2$)$

Emission bands associated to $\mathrm{Eu}^{3+}$ are less intense, but do not present changes in terms of position or shape.

\section{5 - Lifetime measurements and Quantum Efficiency}


The fluorescence lifetime has been measured for all the samples. $\mathrm{Eu}^{2+}$ always shows a

lifetime of the order of few microseconds, and thus impossible to resolve with the excitation pulsed Xe lamp available. Thus, only $\mathrm{Eu}^{3+}$ decay kinetics have been analyzed in details.

Figure 5 shows the normalized $\mathrm{Eu}^{3+}$ fluorescence decay curves for Eu-bearing glasses synthetized in air (red lines) and under $\mathrm{NH}_{3}$-flux (blue lines). For all the samples the curves slightly deviate from the linear slope (monoexponential fit) and this becomes more evident at relative intensity level of $10^{-2}$ and less. At least two exponential components are needed to fit well the experimental curve; however the characteristic lifetime of the components can be varied significantly without influence on the fit quality. Since there are no other evidences of the presence of two different $\mathrm{Eu}^{3+}$ populations (sites), and considering that characteristic lifetimes in case of bi-exponential fit cannot be determined unambiguously, it is reasonable to believe that the origin of the observed non-monoexponential decays is inhomogeneous broadening (for details see discussion section).

The experimental data are well approximated in consideration of lifetime distribution:

$$
\mathrm{I}(\mathrm{t})=\sum_{i} \alpha_{i} e^{-\frac{t}{\tau_{i}}}
$$

showing a single distribution peak (Fig. 5). The $\mathrm{Eu}^{3+}$ mean lifetimes and standard deviations, obtained using the cited approach, are reported in Table 2. The lifetimes for the glasses made in air lie in the range of $2.75-2.9 \mathrm{~ms}$, decreasing for all the glasses after nitridation (Table 2). The probability distributions always show a single peak, and highlight the differences between glasses synthetized in air and under $\mathrm{NH}_{3}$-flux, especially for $\mathrm{NaKPEuN}$ sample.

For Quantum Efficiency (QE) measurements a PTFE coated integrated sphere was used. $\mathrm{Eu}^{3+} \mathrm{QE}$ was measured with excitation at the most intense absorption line ${ }^{5} \mathrm{~L}_{6} . \mathrm{Eu}^{2+} \mathrm{QE}$ was measured with excitation at $310 \mathrm{~nm}$, since at this wavelength it was possible to effectively excite $\mathrm{Eu}^{2+}$ and suppress mostly of the $\mathrm{Eu}^{3+}$ emission. 
$\mathrm{Eu}^{3+} \mathrm{QE}$ slightly varies for different alkali element in the glasses, and reaches up to $77 \%$ in NaKPEu glass. N-treated samples show a drop of the $\mathrm{Eu}^{3+} \mathrm{QE}$, but no trend could be assigned. Indeed, NaKPEuN QE decreases, but of a lower magnitude compared to $\mathrm{K}$ and $\mathrm{Na}$ samples (see Table 2).

$\mathrm{QE}$ for $\mathrm{Eu}^{2+}$ species is quite low for all the samples and does not exceed $2.5 \%$.

\section{Discussions}

Regarding to the glass transition temperature ( $\mathrm{Tg}$ ) values given in Table 1, a mixed alkali effect is clearly shown for both oxide series. This can be discussed in terms of local energetic changes [18]. A stepwise exchange of one cation by another one in a glass network causes a change in local bonding force due to the different field strength of the cations, namely $\mathrm{Na}$ and $\mathrm{K}$. This is the main source for a minimum in ion mobility at about molar fraction of 0.5. However, in the case of viscosity, the network is responsible and not the ion mobility but if the latter has been lowered, the fragments of the remaining network will become smaller, resulting in a more open network. These fragments will have numerous possibilities for changing their positions and as a consequence, the viscous flow will be easier and the glass transition temperature will be lowered. It has been stated [13] that nitridation of metaphosphate glasses is a diffusion controlled mechanism. However, it presents a strong dependence on the glass composition. On one hand, the time after which the maximum nitrogen content is reached is usually shorter for glasses that present lower glass transition temperatures and consequently lower melt viscosities. On the other hand, the value of the maximum nitrogen content has been clearly demonstrated as compositional dependent also. Thus, for a constant nitridation time of $19 \mathrm{~h}$, the $\mathrm{N}$ contents are $0.86 \mathrm{wt} \%$ and $4.42 \mathrm{wt} \%$ for the NaPEu-N and KPEu-N samples, respectively. These values are in accordance with the $\mathrm{Tg}$ of the corresponding oxide glasses, $373^{\circ} \mathrm{C}$ and $353^{\circ} \mathrm{C}$, giving sense to a lower melt viscosity for the KPEu sample and to a more efficient diffusion of ammonia in this melt at $750^{\circ} \mathrm{C}$. 
These values of the nitrogen content can be compared to those obtained for pure alkali metaphosphate glasses $\mathrm{MPO}_{3}$ with $\mathrm{M}=\mathrm{Na}, \mathrm{K}[13,19]$. For these glasses, the nitrogen content reaches values close to $8 \mathrm{wt} \%$, for nitridation conducted during $20 \mathrm{~h}$ at temperatures in the range from $700^{\circ} \mathrm{C}$ to $775^{\circ} \mathrm{C}$, depending on the alkaline element. These largest values are a consequence of the lower viscosity of these melts at the working temperatures.

The presence of nitrogen in the vitreous network causes a general increase in $\mathrm{Tg}$. It has been demonstrated that two new structural units, $\mathrm{PO}_{3} \mathrm{~N}$ and $\mathrm{PO}_{2} \mathrm{~N}_{2}$ are built, where nitrogen are 2 or 3 -fold coordinated to phosphorous [13]. As a result, there is an increase in the glass network reticulation. In addition, the greater covalence of the $\mathrm{P}-\mathrm{N}$ and $\mathrm{P}=\mathrm{N}$ bonds in the $\mathrm{P}(\mathrm{O}, \mathrm{N})_{4}$ tetrahedra, when compared to the $\mathrm{P}-\mathrm{O}$ bonds, contributes to the increase in $\mathrm{Tg}$ also. Furthermore, no evidence of a mixed alkali effect was observed in the case of oxynitride samples. Nevertheless, such a behavior is probably hidden by the smallest increase in $\mathrm{Tg}$, found for the NaPEu sample. This is obviously due to the low nitrogen content measured in the case of the NaPEu-N sample (i.e. $0.86 \mathrm{wt} \%$ ). Another interesting feature is the change of both melting and onset crystallization temperatures. Except in the case of the NaKPEu-N sample, for which no crystallization thermal event was detected, both $\mathrm{Eu}$ and $\mathrm{N}$ increase the onset crystallization temperature and simultaneously decrease the melting temperature. As a result, the Hrubÿ parameter increases yielding to an improvement of the glass stability, which represents the resistance of the glass to devitrification at heating. This behaviour has been previously pointed out in the case of lithium containing silicate oxynitride glasses [20] for which the glass synthesis does not imply the use of an important quenching rate.

In Eu-bearing alkali-phosphate glasses studied by absorption and photoluminescence spectroscopy it was observed both the presence of $\mathrm{Eu}^{2+}$ and $\mathrm{Eu}^{3+}$ species, in different ratios depending on synthesis conditions. In order to study the changes occurring on Eu species in the different glasses, and in particular to understand the average local structure around $\mathrm{Eu}^{3+}$ ions, the fluorescence emission lines ${ }^{5} \mathrm{D}_{0}{ }^{-} \mathrm{F}_{\mathrm{n}}$ (see Fig. 3) have been investigated. ${ }^{5} \mathrm{D}_{0}{ }^{-} \mathrm{F}_{2}$ is an 
electric dipole allowed transition and its intensity is related to variations in $\mathrm{Eu}^{3+}$ local environment, whereas the transition ${ }^{5} \mathrm{D}_{0^{-}}{ }^{7} \mathrm{~F}_{1}$ is a magnetic dipole allowed transition, thus it is slightly influenced by the $\mathrm{Eu}^{3+}$ ion surrounding [2] The intensity ratio of ${ }^{5} \mathrm{D}_{0-}{ }^{7} \mathrm{~F}_{2}$ to ${ }^{5} \mathrm{D}_{0}{ }^{-} \mathrm{F}_{1}$ increases as the degree of Eu-O covalence increases [21] and when symmetry of site decreases [22]. Furthermore, Bouchouicha and coauthors [23] reported changes occurring to non-degenerate ${ }^{5} \mathrm{D}_{0-}{ }^{7} \mathrm{~F}_{0}$ emission lines as variations in the $\mathrm{Eu}^{3+}$ local environment.

Herrmann et al. [24] described the transition at $613 \mathrm{~nm}\left({ }^{5} \mathrm{D}_{0}{ }^{7} \mathrm{~F}_{2}\right)$ as very sensitive to the local environment around $\mathrm{Eu}^{3+}$ but in our glasses we did not observe noticeable variations. In the $\mathrm{Eu}^{3+}$ luminescence bands assigned to magnetic-dipole ${ }^{5} \mathrm{D}_{0-}{ }^{7} \mathrm{~F}_{1}$ transition, it was possible to observe three resolved components (Stark levels), and previous studies, (i.e. [25,26]), associated the presence of three peaks for ${ }^{5} \mathrm{D}_{0^{-}}{ }^{7} \mathrm{~F}_{1}$ transition as indication of low symmetry around the $\mathrm{Eu}^{3+}$ ions. In order to study this transition, a deconvolution of the background subtracted signal was carried out. The three Gaussian components used for the deconvolution of our glasses are very similar (Fig. 6) and since the maximum splitting in Stark levels is proportional to the crystal-field strength, it is possible to affirm that no strong variations in the $\mathrm{Eu}^{3+}$ local environment occur by substituting the alkali element.

In order to understand the chemical control on $\mathrm{Eu}^{3+}$ ions, we studied the so-called asymmetric ratio $\mathrm{I}\left({ }^{5} \mathrm{D}_{0}{ }^{-} \mathrm{F}_{2}\right) / \mathrm{I}\left({ }^{5} \mathrm{D}_{0}{ }^{7} \mathrm{~F}_{1}\right)$ (Table 2$)$. For the $\mathrm{Eu}^{3+}$ species, the asymmetric ratio of the end-members follows the evolution of the electric-dipole transition, which is especially sensible to the crystal field (and in turn, to deviation from inversion symmetry). A small increase of the asymmetric ratio is always observed for K-bearing samples, and it is attributed to increasing asymmetry and higher degree of covalence between europium and oxygen ions. However, it must be noticed that the modifications occurring around $\mathrm{Eu}^{3+}$ ions are really limited, and the luminescence data here obtained suggest the presence of $\mathrm{Eu}^{3+}$ in just one site 
distribution. In fact, the observed changes are not strong enough to change significantly the $\mathrm{Eu}^{3+}$ emission spectra originated from shielded intra- $4 f$ orbital transitions, even if it was possible to notice variations in the decay and quantum efficiency occurring with changing of composition, as well as, after nitridation. The decrease of QE, especially after the Ntreatment, could be explained e.g. by increasing of absorption due introducing of some defects, or reducing impurities in the glass. The changes in lifetime indicate more some modifications in the local environment of the optical centers, particularly when comparing a glass before and after nitridation. For all the samples observed lifetime is comparable with literature data and typical for $\mathrm{Eu}^{3+}$ (e.g. see $[15,24,27]$ and references therein). The slightly nonexponential decay law could be an evidence of an energy transfer or additional decay mechanism observed in the glasses. However, since no additional doping elements are present in the glasses, i.e. there is no possibility for energy transfer to another optical center, and concentration quenching for $\mathrm{Eu}^{3+}$ are usually observed at much higher doping levels [28], we believe that the nonexponential behavior is an evidence of inhomogeneous broadening due to site to site crystal field variations. Introduction of nitrogen into the glass matrix after the nitridation probably changes the local environment of the optical centers causing a decrease of lifetime, but it is important to note that still just one distribution band over the lifetimes is observed (see Table 2), and there are not further evidences of various $\mathrm{Eu}^{3+}$ sites in the studied glasses. These results are in agreement with previous studies on simplified and multicomponent silicate glasses [7,29], where it was observed that the bulk chemistry does not produce strong modifications on the $\mathrm{Eu}^{3+}$ local environment.

Contrary to the trivalent europium, $\mathrm{Eu}^{2+}$ absorption and luminescence bands are strongly influenced by the bulk composition. The results obtained shown that the $\mathrm{Eu}^{2+}$ broad fluorescence band shifts at higher wavelength by substituting the alkali cation, in the order $\mathrm{Na}<\mathrm{NaK}<\mathrm{K}$. Hence, its position is strongly dependent on the chemistry. To explain this chemical control we used the optical basicity concept ([30,31]). In Figure 7 it is shown the 
maximum of the $\mathrm{Eu}^{2+}$ emission bands as a function of the calculated optical basicity $(\Lambda)$.

There is a strong link between the optical basicity parameter and the position of the $\mathrm{Eu}^{2+}$ luminescence band and the trend that we identify in Figure 7 for phosphate glasses matches that observed for other glass compositions (borate [5] and silicate glasses [8]).

All the variations observed in the phosphate glasses here investigated are mainly related to the chemistry, and in particular on the alkali cation present. The optical basicity concept has been proved to be an appropriate parameter to predict the variations occurring on Eu luminescence properties. To explain this strong link we should consider the component activities, and in particularly it is mandatory taking into account polymerization reactions governing the extension and distribution of the units. In fact, the ability to transfer fractional electronic charges is well represented by the optical basicity concept. Both chemical variations - substitution of $\mathrm{K}$ for $\mathrm{Na}$, and synthesis under $\mathrm{NH}_{3}$-flux in a glassy carbon crucible - induce a redshift of emission spectra. Such a redshift, following the nephelauxetic effect, can be assigned either to a decrease of the distance between the $\mathrm{Eu}^{2+}$ and its ligands, and/or an increase of covalency. If we envision that a direct substitution of $\mathrm{Na}$ by $\mathrm{K}$ as second neighbors of the Eu will take place, it should induce a redshift since the ionic strength field of $\mathrm{K}$ is lower than that of $\mathrm{Na}$ and then the $\langle\mathrm{Eu}-\mathrm{O}\rangle$ distances will decrease. Moreover, if we take into account a direct substitution of $\mathrm{O}$ by $\mathrm{N}$ in Eu first coordination sphere, this new chemical bond should be more covalent since $\mathrm{N}$ has a lower electronegativity than $\mathrm{O}$. This should also lead to a redshift. Farias and coauthors [8] verified that by increasing silica concentration (and in turn, by changing the optical basicity) there is a promotion of the $\mathrm{Eu}^{3+}->\mathrm{Eu}^{2+}$ conversion and a subsequent shift of the $\mathrm{Eu}^{2+}$ emission band toward red. In our study we observed that Ntreatment in glassy carbon crucible enhances the presence of the reduced species, and it influences the position of the $\mathrm{Eu}^{2+}$ luminescence. 
The chromaticity diagram obtained from the photoluminescence measurements is reported in Figure 8 and it clear shows that the coordinates vary systematically with the alkaline element used, as well as with the synthesis conditions. The systematic variation from blue to red of the global emission of our new phosphors, at their excitation maximum, is mainly due to a relative increase of the $\mathrm{Eu}^{2+}$ emission band compared to the trivalent one, more than to the individual redshift of each emission. This was clearly seen in Figure 4 where $\mathrm{Eu}^{3+}$ emission drastically decreases if $\mathrm{Eu}^{2+}$ emission intensity is normalized on its maximum.

\section{Conclusions and final remarks}

Alkali phosphate glasses have been used to study the chemical tunability of Eu emission. The evolution of the glass transition and melting temperatures are consistent from each glass composition. The addition of $\mathrm{Eu}$ increases $\mathrm{Tg}$ by more than $10^{\circ} \mathrm{C}$ and the nitridation by more than $45^{\circ} \mathrm{C}$. This can be easily understood as REE usually increase the viscosity due to their big size that prevents easy structural relaxations. The introduction of N, even in small quantity, highly increases the viscosity due to its higher valence state compare to oxygen which is responsible for the greater reticulation of the oxynitride vitreous network. The effect is opposite on the melting temperature where for each composition a decrease of at least $10{ }^{\circ} \mathrm{C}$ is observed for Eu bearing sample, and $55^{\circ} \mathrm{C}$ for nitridated samples. In fact, the introduction of more elements, as $\mathrm{Eu}$ and $\mathrm{N}$, by entropic contribution induces an eutectic effect. It ends up that from a synthesis point of view the $\mathrm{K}$ or mixed $\mathrm{Na}-\mathrm{K}$ composition will be the best in term of energy saving during production since their melting temperatures are the smallest. The systematic decrease of the difference between the melting and glass transition temperature induces a decrease of the glass ability when completely substituting $\mathrm{Na}$ for $\mathrm{K}$, with an evident alkali-mixed effect for the Na-K composition.

The photoluminescence studies clearly show that $\mathrm{Eu}^{2+}$ emission band shifts toward red by substituting the alkali cation, in the order $\mathrm{Na}<\mathrm{NaK}<\mathrm{K}$, in agreement with the calculated 
optical basicity, whereas the luminescence data here obtained suggest the presence of $\mathrm{Eu}^{3+}$ in just one site distribution. The large shift toward higher wavelengths, observed for samples synthetized in air, indicates that the network modifier ions strongly affect the nature of the $\mathrm{Eu}^{2+}-\mathrm{O}$ bond, and consequently, its crystal-field strength.

Nitridation at $750^{\circ} \mathrm{C}$ allowed incorporating high amount of $\mathrm{N}$ in the glasses, and this procedure leads to increasing glass transition temperatures and glass forming ability, thus suggesting an important nitrogen/oxygen substitution within $\mathrm{PO}_{4}$ tetrahedra. Moreover, the synthesis approach increased the amount of $\mathrm{Eu}^{2+}$ in the glasses and a relevant broadening, as well as a slightly shift to higher wavelengths of $\mathrm{Eu}^{2+}$ emission band was observed.

The systematic shift of Eu emission is primarily caused by the increase of the $\mathrm{Eu}^{2+}$ emission band, compared to the $\mathrm{Eu}^{3+}$ one. This variation can have at least three origins:

- evolution of the redox ratio during N-treatment in glassy carbon crucible: absorption spectroscopy results have shown a decrease of the $\mathrm{Eu}^{3+}$ band intensities, up to $20 \%$;

- evolution of $\mathrm{Eu}^{2+}$ cross section: in the case of substitution of $\mathrm{Na}$ by $\mathrm{K}$, the modification of the emission was associated more on the maximum position shift than on the intensity;

- introduction of an energy transfer mechanism between defects and $\mathrm{Eu}^{2+}$. The presence of this defect population can be inferred from the very strong absorption increase below 400nm.

As redox variation cannot explain by itself the variation of the intensity ratio between $\mathrm{Eu}^{2+}$ and $\mathrm{Eu}^{3+}$, than evolved between 40 and $85 \%$, at least an over origin must be incriminated.

The glass compositions studied here will be subject of crystallization studies in order to obtain congruent minerals and in turn, to recover REE. Thus, starting from phosphate glasses, which can be more easily prepared compared to silicate glasses, first of all, it would be possible to adjust the chemistry in order to get the desired lighting, and second it would be possible to recycle the europium (and others REE) ions. 
The authors are grateful for the financial support of the Bayerisch-Französisches

Hochschulzentrum (BFHZ). The authors thank two anonymous reviewers for their valuable comments and suggestions.

\section{Appendix A}

\section{A.1 Carbothermal Reduction Nitridation vs. Ammonolysis}

Carbon is well known to act as reducing agent, especially when temperature increases. In the Carbothermal Reduction Nitridation ( $\mathrm{CRN})$ method, a mixture of oxide powders and carbon (activated carbon, graphite powder) is treated at high temperature under flowing $\mathrm{N}_{2}$. Graphite powder is the reducing agent and reacts with the metal oxide forming $\mathrm{CO}_{2}$ or $\mathrm{CO}$, depending on the temperature range. Carbon should be added in quantities usually taken between 60 and $120 \%$ molar of the total oxygen quantity in the starting material [30]. However, this quantity has to be optimized to avoid the formation of secondary oxide phases when carbon is too low, and if it is too high, the quantity of carbonated residue becomes too important and can harm luminescent properties in the case of phosphor synthesis. It has been shown that fluoride phosphate glasses melted in carbon crucibles in an inert atmosphere have much higher UV transmission than melted material in platinum crucibles [31]. The increase of the UV transmission was attributed to a reduction of $\mathrm{Fe}^{3+}$ to $\mathrm{Fe}^{2+}$ due to carbon crucible-glass interaction [31].

Nevertheless, in this work, the glass synthesis has been conducted in a glassy carbon crucible (SIGRADUR®). Glassy carbon has an extreme corrosion resistance and is definitively the most oxidation resistant carbon material. Due to its closed microstructure (open porosity $<1 \%$ ), it does not form intercalation compounds and does not show any wetting by ceramic melts. This is particularly advantageous in glass synthesis, and we do not observe any corrosion of the crucible after nitridation experiments. Moreover, the glasses were always 
easy to remove from the crucible. These observations give sense towards a reduction-

nitridation favored preferentially by ammonia than carbon.

The reduction-nitridation behaviour of $\mathrm{CRN}$ and Ammonolysis can be compared by using the diagrammatic representation developed by Ellingham which is useful for comparing the feasibility of reactions for a variety of compounds [32]. According to the Ellingham's approximation:

$$
\Delta_{r} G_{T}^{0}=\Delta_{r} H_{298}^{0}-T \Delta_{r} S_{298}^{0}
$$

the standard Gibbs energy changes, for the following equilibria, can be plotted versus temperature,

$$
\begin{gathered}
2 \mathrm{C}+\mathrm{O}_{2} \leftrightarrows 2 \mathrm{CO} \\
\mathrm{C}+\mathrm{O}_{2} \leftrightarrows \mathrm{CO}_{2} \\
4 / 3 \mathrm{NH}_{3}+\mathrm{O}_{2} \leftrightarrows 2 / 3 \mathrm{~N}_{2}+2 \mathrm{H}_{2} \mathrm{O}
\end{gathered}
$$

where, the latest equilibrium can be considered as the superposition of the two simple equilibria:

(1) $4 / 3 \mathrm{NH}_{3} \leftrightarrows 2 / 3 \mathrm{~N}_{2}+2 \mathrm{H}_{2}$

(2) $2 \mathrm{H}_{2}+\mathrm{O}_{2} \leftrightarrows 2 \mathrm{H}_{2} \mathrm{O}$

then

$$
\begin{gathered}
\Delta_{r} H_{298}^{0}=\Delta_{r} H_{298}^{0}(1)+\Delta_{r} H_{298}^{0}(2) \\
\Delta_{r} H_{298}^{0}=-\frac{4}{3} \Delta_{f} H_{298}^{0}\left(N H_{3}\right)+2 \Delta_{f} H_{298}^{0}\left(H_{2} O\right)
\end{gathered}
$$

and

$$
\Delta_{r} S_{298}^{0}=-\frac{4}{3} \Delta_{f} S_{298}^{0}\left(N H_{3}\right)+2 \Delta_{f} S_{298}^{0}\left(H_{2} O\right)
$$

The thermodynamic data for the reactants and products are taken from [33]. Data for the stable phases can be used to produce the Ellingham diagram, as shown in Figure A1, where the standard Gibbs energy for the three considered equilibria are plotted vs. temperature. 


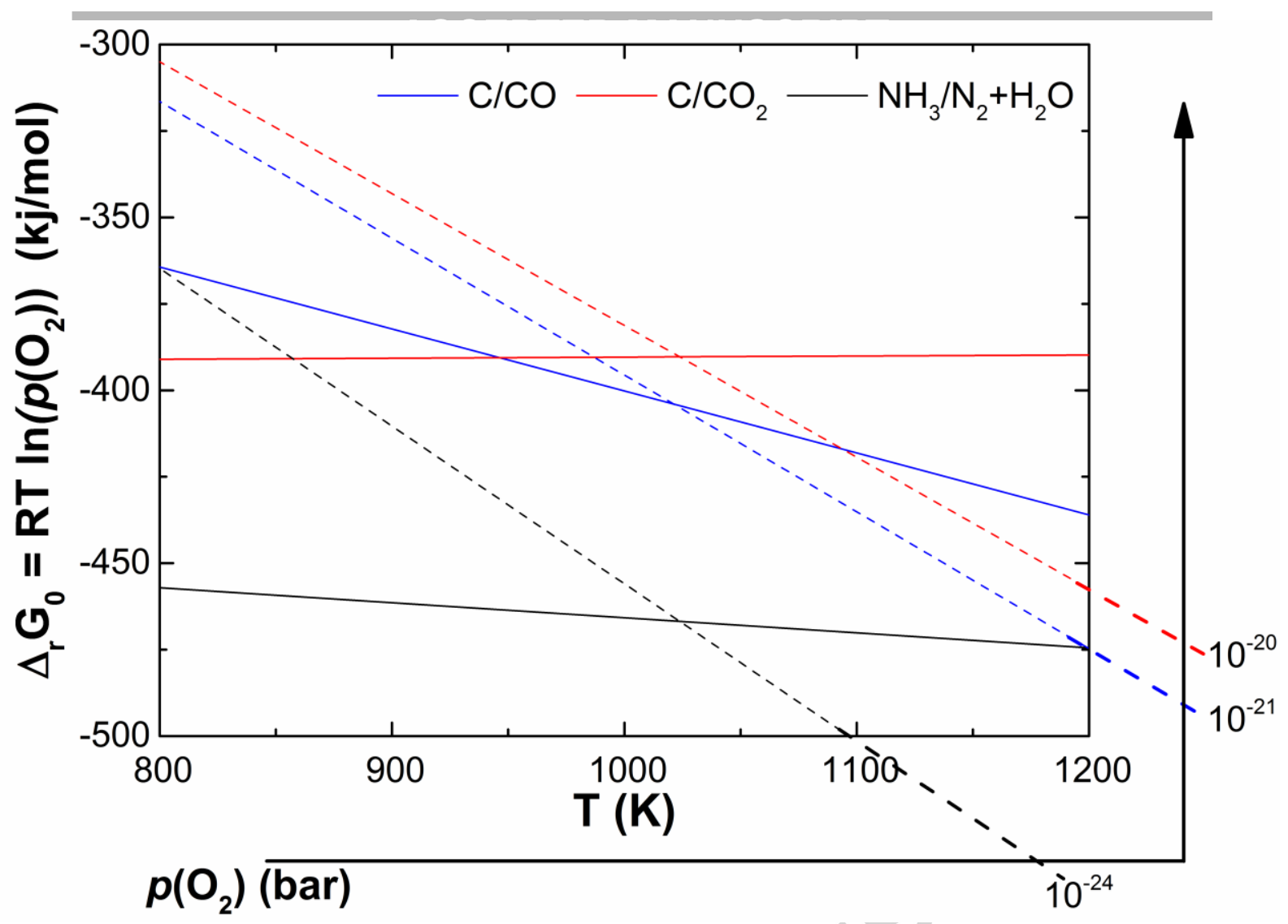

Figure A1: Ellingham diagram showing the temperature dependence of standard Gibbs energy change and of the residual oxygen pressure (dashed lines) for the considered equilibria (solid lines). The variation of the oxygen partial pressure $\left(\mathrm{pO}_{2}\right)$ is shown.

All the reactions displayed on Figure A1 are written with one mole of oxygen as the reactant. An advantage of plotting the curves in this diagram is that it would be possible to define immediately the best reducing agent, and in our case, ammonia would be dissociated in contact with any oxide $\left(\mathrm{CO}\right.$ or $\left.\mathrm{CO}_{2}\right)$ that belongs to lines appearing above it. From the graph (Fig. A1), it obviously appears that at $1023 \mathrm{~K}$, in presence of $\mathrm{C}$, the ammonia dissociation is largely favoured while carbon cannot be oxidized, confirming the direct observation made after the experiments. In addition, the residual oxygen pressure at equilibrium is lower when considering ammonia as the reducing and nitriding medium.

\section{A2. $\mathrm{NH}_{3}$ dissociation and equilibrium constant at $1023 \mathrm{~K}$}

Considering the following equilibrium:

$$
\mathrm{NH}_{3} \leftrightarrows 1 / 2 \mathrm{~N}_{2}+3 / 2 \mathrm{H}_{2} \mathrm{O}
$$


the equilibrium constant $\left(K_{e q}\right)$ is: CEPTED MANUSCRIPT

$$
K_{e q}=\frac{\left(\frac{1}{2} \alpha\right)^{1 / 2}\left(\frac{3}{2} \alpha\right)^{3 / 2}}{\left(1-\alpha^{2}\right)}
$$

And at equilibrium (see Table A1), the Gibbs free energy (at temperature T) is:

$$
\Delta_{r} G_{T}=\Delta_{r} G_{T}^{0}-R T \ln K_{e q}=0
$$

The standard Gibbs energy change for the $\mathrm{NH}_{3}$ dissociation at temperature $\mathrm{T}$ can be calculated using thermodynamical tables and, thus it is possible to calculate the equilibrium constant:

$$
\begin{gathered}
\Delta_{r} G_{1023}^{0}=-R T \ln K_{e q} \\
\Delta_{r} G_{1023}^{0}=-55.2 \mathrm{~kJ} / \mathrm{mol} . \\
\mathrm{K}_{\text {eq }}=659
\end{gathered}
$$

then, the dissociation coefficient $(\alpha)$ for $\mathrm{NH}_{3}$ dissociation at $1023 \mathrm{~K}$, is

$$
\alpha=0.9996
$$

Table A1: reactant and product quantities at both the initial and equilibrium steps.

\begin{tabular}{|c|c|c|c|c|c|}
\hline & time & $\mathrm{NH}_{3(\mathrm{~g})}$ & $1 / 2 \mathrm{~N}_{2}$ & $3 / 2 \mathrm{H}_{2(\mathrm{~g})}$ & $\mathrm{n}_{\mathrm{g}}$ \\
\hline Initial & $\mathrm{t}=0$ & 1 & 0 & 0 & 1 \\
\hline Equilibrium & $\mathrm{t}_{\mathrm{eq}}$ & $1-\alpha$ & $1 / 2 \alpha$ & $3 / 2 \alpha$ & $1+\alpha$ \\
\hline
\end{tabular}

\section{References}

[1]R. Reisfeld, R.A. Velapoldi, L. Boehm, M. Ish-Shalom, J. Phys. Chem. 75 (1971) 39803983. 10.1021/j100695a012.

[2]J.A. Capobianco, P.P. Proulx, M. Bettinelli, F. Negrisolo, Phys. Rev. B 42 (1990) 59365944. 10.1103/PhysRevB.42.5936. 
[3]Z. Lian, J. Wang, Y. Lv, S. Wang, Q. Su, J. Alloy Compd. 430 (2007) 257-261. 10.1016/j.jallcom.2006.05.002.

[4]C. Zhu, Y. Yang, X. Liang, S. Yuan, G. Chen, J. Am. Chem. Soc. 90 (2007) 2984-2986. 10.1111/j.1551-2916.2007.01775.x.

[5]C. Wang, M. Peng, N. Jiang, X. Jiang, C. Zhao, J. Qiu, Mater. Lett. 61 (2007) 3608-3611. 10.1016/j.matlet.2006.11.133.

[6]R. Morris, L. Haskin, Geochim Cosmochim Ac 38 (1974) 1435-1445. 10.1016/00167037(74)90097-0.

[7]M.R. Cicconi, G. Giuli, E. Paris, W. Ertel-Ingrisch, P. Ulmer, D.B. Dingwell, Am. Mineral. 97 (2012) 918-929. 10.2138/am.2012.4041.

[8]A.M. Farias, M. Sandrini, Viana, José Renato M., M.L. Baesso, A.C. Bento, J.H. Rohling, Y. Guyot, D. de Ligny, Nunes, Luiz Antônio O., F.G. Gandra, J.A. Sampaio, S.M. Lima, Andrade, Luis Humberto C., A.N. Medina, Mater Chem Phys 156 (2015) 214-219. 10.1016/j.matchemphys.2015.03.002.

[9]A.P. Jones, F. Wall, C.T. Williams, Rare earth minerals: Chemistry, origin and ore deposits, Chapman \& Hall, London, 1996.

[10]T.W. Ellis, F.A. Schmidt, L.L. Jones, Methods and opportunities in the recycling of rare earth based materials, United States. Dept. of Energy; Distributed by the Office of Scientific and Technical Information, U.S. Dept. of Energy, Washington, D.C, Oak Ridge, Tenn, 1994. [11]I.W. Donald, J. of Mat. Sci. 28 (1993) 2841-2886. 10.1007/BF00354689.

[12]A. Le Sauze, R. Marchand, J. Non-Cryst. Solids 263-264 (2000) 285-292. 10.1016/S0022-3093(99)00673-0.

[13]F. Muñoz, L. Pascual, A. Durán, J. Rocherullé, R. Marchand, Comptes Rendus Chimie 5 (2002) 731-738. 10.1016/S1631-0748(02)01434-0.

[14]M. Yang, J. Oró-Solé, A. Kusmartseva, A. Fuertes, J.P. Attfield, J. Am. Chem. Soc. 132 (2010) 4822-4829. 10.1021/ja910745b.

[15]K. Linganna, C.K. Jayasankar, Spectrochim. Acta A 97 (2012) 788-797. 10.1016/j.saa.2012.07.031

[16]J. Pisarska, M. Sołtys, L. Żur, W.A. Pisarski, C.K. Jayasankar, Appl Phys B 116(4) (2014) 837-845. 10.1007/s00340-014-5770-9

[17]A. Hrubý, Czech J Phys 22 (1972) 1187-1193. 10.1007/BF01690134.

[18]A.H. Dietzel, Phys. Chem. Glasses 24 (1983) 172-180.

[19]X. Lei, D.E. Day, J. Am. Chem. Soc. 72 (1989) 1601-1603. 10.1111/j.11512916.1989.tb06289.x.

[20]J. Rocherulle, J. Guyader, P. Verdier, Y. Laurent, J Mater Sci 24 (1989) 4525-4530. 10.1007/BF00544539.

[21]H. You, M. Nogami, J. Phys. Chem. B 108 (2004) 12003-12008. 10.1021/jp0486245. [22]M. Gaft, R. Reisfeld, G. Panczer, Modern luminescence spectroscopy of minerals and materials, Springer, Berlin, New York, 2005.

[23]H. Bouchouicha, G. Panczer, D. de Ligny, Y. Guyot, M.L. Baesso, L. Andrade, S.M. Lima, R. Ternane, J. Lumin. 169 (2016) 528-533. 10.1016/j.jlumin.2014.11.054.

[24]A. Herrmann, S. Fibikar, D. Ehrt, J. Non-Cryst. Solids 355 (2009) 2093-2101. 10.1016/j.jnoncrysol.2009.06.033. 
[25]V. Venkatramu, D. Navarro-Urrios, P. Babu, C.K. Jayasankar, V. Lavín, J. Non-Cryst.

Solids 351 (2005) 929-935. 10.1016/j.jnoncrysol.2005.02.010.

[26]W.A. Pisarski, J. Pisarska, G. Dominiak-Dzik, W. Ryba-Romanowski, J. Alloy Compd. 484 (2009) 45-49. 10.1016/j.jallcom.2009.05.039.

[27]S.S. Babu, P. Babu, C.K. Jayasankar, W. Sievers, T. Tröster, G. Wortmann, J. Lumin. 126 (2007) 109-120. 10.1016/j.jlumin.2006.05.010.

[28]G. Gao, L. Wondraczek, J. Mater. Chem. C 2 (2014) 691-695. 10.1039/C3TC31660B.

[29]M.R. Cicconi, G. Giuli, E. Paris, D.B. Dingwell, J. Non-Cryst. Solids 356 (2010) 17491753. 10.1016/j.jnoncrysol.2010.06.029.

[30]J.A. Duffy, M.D. Ingram, J. Non-Cryst. Solids 21 (1976) 373-410. 10.1016/00223093(76)90027-2.

[31]R. Moretti, Annals of Geophysics 48 (2005).

[30]T. Kurushima, G. Gundiah, Y. Shimomura, M. Mikami, N. Kijima, A.K. Cheetham, J. Electrochem. Soc. 157 (2010) J64. 10.1149/1.3276677.

[31]D. Ehrt, W. Seeber, J. Non-Cryst. Solids 129 (1991) 19-30. 10.1016/00223093(91)90076-I.

[32]K.T. Jacob, R. Verma, R.M. Mallya, J. of Mat. Sci. 37 (2002) 4465-4472. 10.1023/A:1020649913206.

[33]M. Bernard, F. Busnot, Usuel de chimie générale et minérale, Dunod, Paris, 1996.

Table 1: Compositions (mol\%), optical basicity $(\Lambda)$ and some properties of the phosphate glasses. Eu-bearing glasses have been doped with $1 \mathrm{wt} \% \mathrm{Eu}_{2} \mathrm{O}_{3}$

\begin{tabular}{lcccccccccc}
\hline Sample & $\mathbf{P}_{\mathbf{2}} \mathbf{O}_{\mathbf{5}}$ & $\mathbf{C a O}$ & $\mathbf{N a}_{\mathbf{2}} \mathbf{O}$ & $\mathbf{K}_{\mathbf{2}} \mathbf{O}$ & $\begin{array}{c}\mathbf{N} \\
\mathbf{c o n t e n t} \\
(\mathbf{w t} \mathbf{\%})\end{array}$ & $\begin{array}{c}\mathbf{T g} \\
\left({ }^{\circ} \mathbf{C}\right)\end{array}$ & $\begin{array}{c}\mathbf{T m} \\
\left({ }^{\circ} \mathbf{C}\right)\end{array}$ & $\begin{array}{c}\mathbf{T x} \\
\left({ }^{\circ} \mathbf{C}\right)\end{array}$ & $\begin{array}{c}(\mathbf{T x}-\mathbf{T g}) / \\
(\mathbf{T m}-\mathbf{T x}) \S\end{array}$ & $\Lambda$ \\
\hline $\mathrm{NaP}$ & 50 & 20 & 30 & - & - & 351 & 735 & 547 & 1.04 & 0.52 \\
NaPEu & 50 & 20 & 30 & & - & 373 & 706 & 586 & 1.78 & \\
NaPEu-N & 50 & 20 & 30 & - & 0.86 & 392 & 678 & 602 & 2.76 & \\
NaKP & 50 & 20 & 15 & 15 & - & 320 & 700 & 565 & 1.81 & 0.53 \\
NaKPEu & 50 & 20 & 15 & 15 & - & 331 & 692 & 568 & 1.91 & \\
NaKPEu-N & 50 & 20 & 15 & 15 & 4.42 & 395 & - & - & - & \\
KP & 50 & 20 & - & 30 & - & 342 & 698 & 480 & 0.63 & 0.54 \\
KPEu & 50 & 20 & - & 30 & - & 353 & 680 & 499 & 0.81 & \\
KPEu-N* & 50 & 20 & - & 30 & 4.45 & 377 & 644 & 534 & 1.43 & \\
\hline
\end{tabular}

$\mathrm{Tg}=$ glass transition temperature $\mathrm{Tm}=$ melting temperature $\mathrm{Tx}=$ crystallization temperature. *Partially crystallized $\left(\mathrm{KCa}\left(\mathrm{PO}_{3}\right)_{3}\right) ; \S$ Hrubÿ parameter [17]

Table 2: Photoluminescence results for the investigated glasses. 


\begin{tabular}{|c|c|c|c|c|c|c|}
\hline \multirow[b]{3}{*}{ Sample } & \multicolumn{5}{|c|}{ ACCEPTED W/ANUSCRIPT } & \\
\hline & \multicolumn{3}{|c|}{$\mathbf{E u}^{2+}$} & \multicolumn{3}{|c|}{$\mathbf{E u}^{3+}$} \\
\hline & Ex $(\mathbf{n m})$ & Em (nm) & $\begin{array}{c}\text { FWHM } \\
( \pm 0.5 \mathrm{~nm})\end{array}$ & $\mathbf{I}\left({ }^{5} \mathbf{D}_{0^{-}}{ }^{7} \mathbf{F}_{2}\right) /\left({ }^{5} \mathbf{D}_{0^{-}}{ }^{7} \mathbf{F}_{1}\right)$ & $\begin{array}{c}\text { Lifetime } \\
(\mathrm{ms})^{\S} \\
\tau\end{array}$ & $\begin{array}{l}\text { QE } \\
(\%)\end{array}$ \\
\hline $\mathrm{NaPEu}$ & 321 & 422 & 91.5 & 3.31 & $2.86(69)$ & 69 \\
\hline $\mathrm{NaKPEu}$ & 324 & 435 & 95.5 & 3.31 & $2.90(66)$ & 77 \\
\hline $\mathrm{KPEu}$ & 330 & 470 & 107.1 & 3.62 & $2.75(64)$ & 60 \\
\hline $\mathrm{NaPEu} \mathrm{N}$ & 327 & 432 & 98.9 & 3.49 & $2.70(73)$ & 39 \\
\hline NaKPEu N & 335 & 445 & 109.4 & 4.18 & $2.22(58)$ & 60 \\
\hline KPEu N & 360 & 472 & 108.0 & 4.18 & $2.50(67)$ & 37 \\
\hline
\end{tabular}

$\S$ in brackets the standard deviation of the lifetime distribution.

Fig.1 - Differential Scanning Calorimetry (DSC) curves for Eu-bearing alkali phosphate glasses synthetized in air. Glass transition (Tg), onset crystallization peak (Tx) and melting temperature $(\mathrm{Tm})$ are reported. The clear mixed alkali effect on the glass transition temperatures of the three glasses is highlighted in the inset.

Fig. 2 - Optical absorption spectra for undoped alkali phosphate glasses (black lines), and for Eu-bearing glasses synthetized in air (red lines) or under $\mathrm{NH}_{3}$-flux (blue lines). Assignments of the bands for the excited states from the ground states $(7 \mathrm{~F})$ of $\mathrm{Eu}^{3+}$ are reported. N-treated NaKP spectrum was vertically translated for sake of clarity.

Fig. 3 - Excitation and PL spectra for Eu-bearing alkali phosphate glasses, respectively under $392 \mathrm{~nm}$ excitation and $613 \mathrm{~nm}$ emission (a- upper panels) and at the maximum of the $\mathrm{Eu}^{2+}$ fluorescence (arrows) and under $330 \mathrm{~nm}$ (b - lower panels). In the upper panels all the transitions are associated to $\mathrm{Eu}^{3+}$ and do not significantly change, whereas in the lower panels both emission and excitation $\mathrm{Eu}^{2+}$ bands show a shift toward red region by substituting $\mathrm{K}$ for $\mathrm{Na}$. 
Fig. 4 - Normalised excitation and emission spectra for alkali-bearing samples synthetized in air (black lines) and under $\mathrm{NH}_{3}$ flux (red lines), respectively under $330 \mathrm{~nm}$ excitation and at the maximum of the emission (arrows) $\mathrm{The}^{2} \mathrm{u}^{2+}$ bands are clearly broader and shifted at higher wavelengths after $\mathrm{N}$-treatment. The sharp peaks associated to $\mathrm{Eu}^{3+}$ strongly decrease.

Fig. 5 - Fluorescence decay curves at 613 nm, under $392 \mathrm{~nm}$ excitation, for Eu-bearing phosphate glasses synthetised in air (red lines) and under $\mathrm{NH}_{3}$-flux (blue lines), along with the fitting functions (black lines). The curves are normalised in intensity to allow a better comparison, and all of them show non-monoexponential decay. The lifetime probability distributions are reported for all the glasses. N-treated samples always show shorter lifetime.

Fig. 6 - Background subtracted luminescence spectra corresponding to ${ }^{5} \mathrm{D}_{0^{-}}{ }^{7} \mathrm{~F}_{1}$ transitions of $\mathrm{Eu}^{3+}$ ions in alkali phosphate glasses. The Gaussian components used are very similar, and only a small variation in the FWHM is noticeable.

Fig. 7 - Maximum of the $\mathrm{Eu}^{2+}$ emission bands as a function of the calculated optical basicity $(\Lambda)$. Literature data are reported for comparison for borate [8] and silicate [5] glasses.

Fig. 8 - CIE 1976 chromaticity diagram for the alkali-bearing phosphate glasses synthetized in air (stars) and under $\mathrm{NH}_{3}$-flux (circles). The emission can be systematically tuned by changing the chemistry.

Figure 1: 


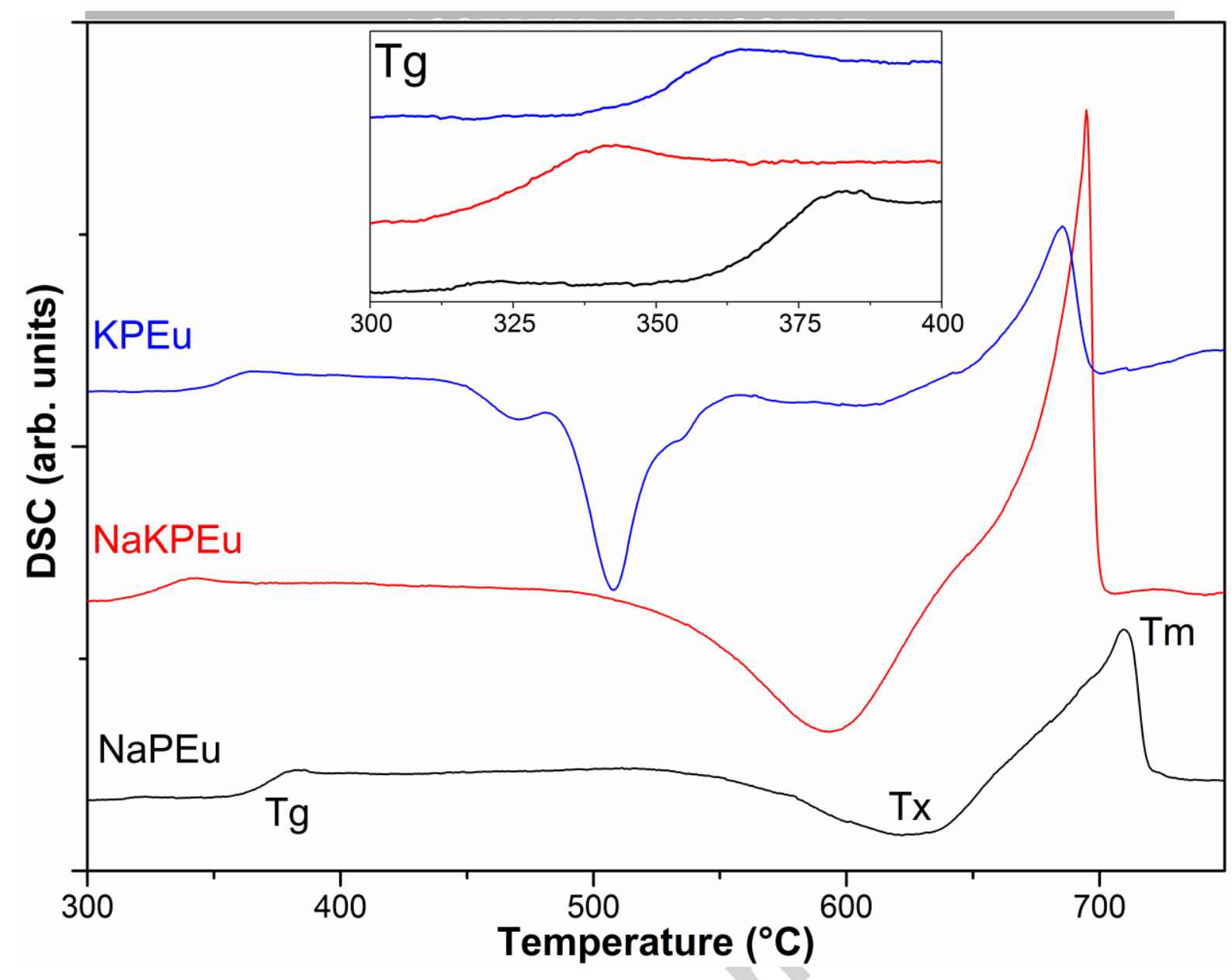


Figure 2

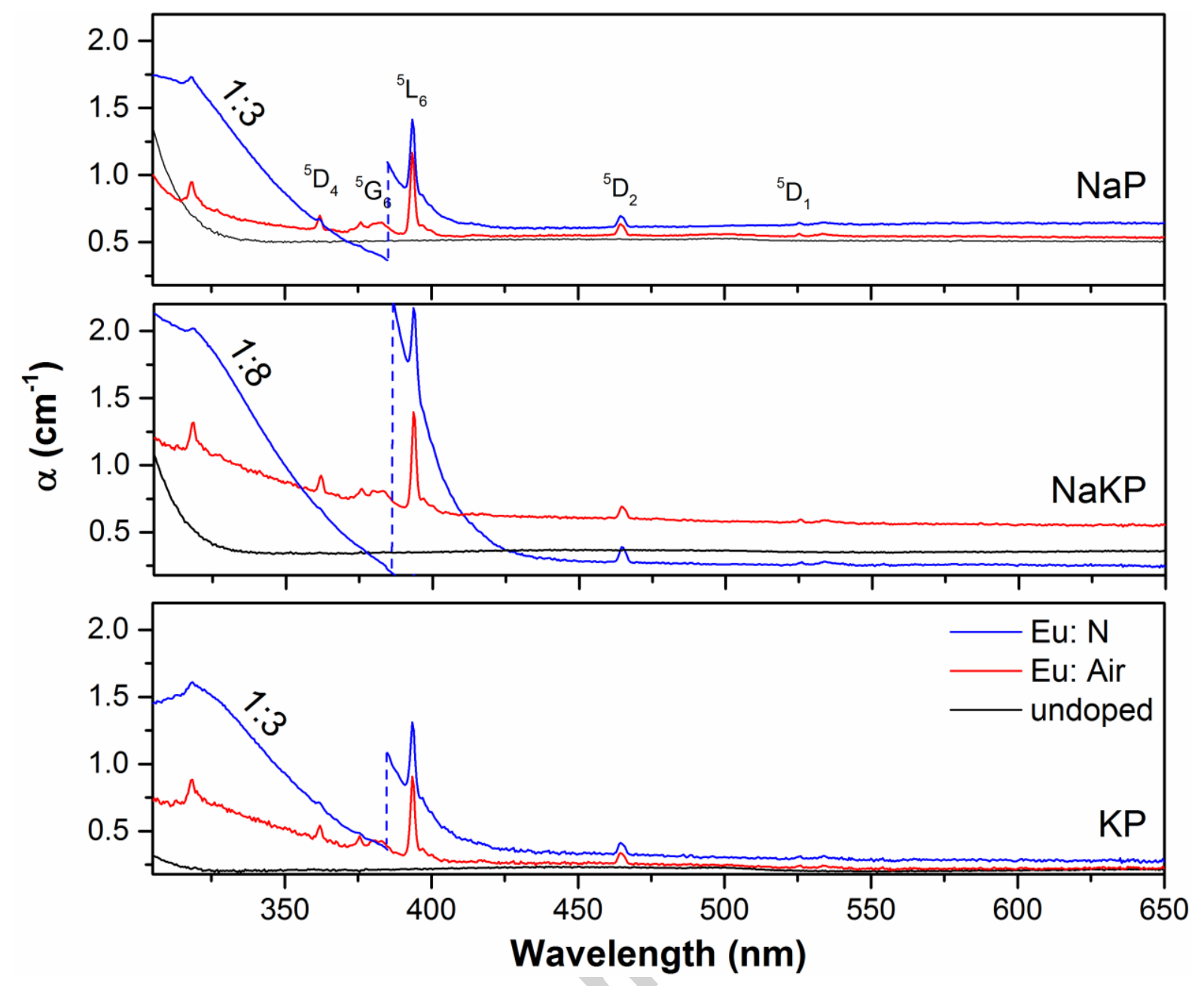

Figure 3 

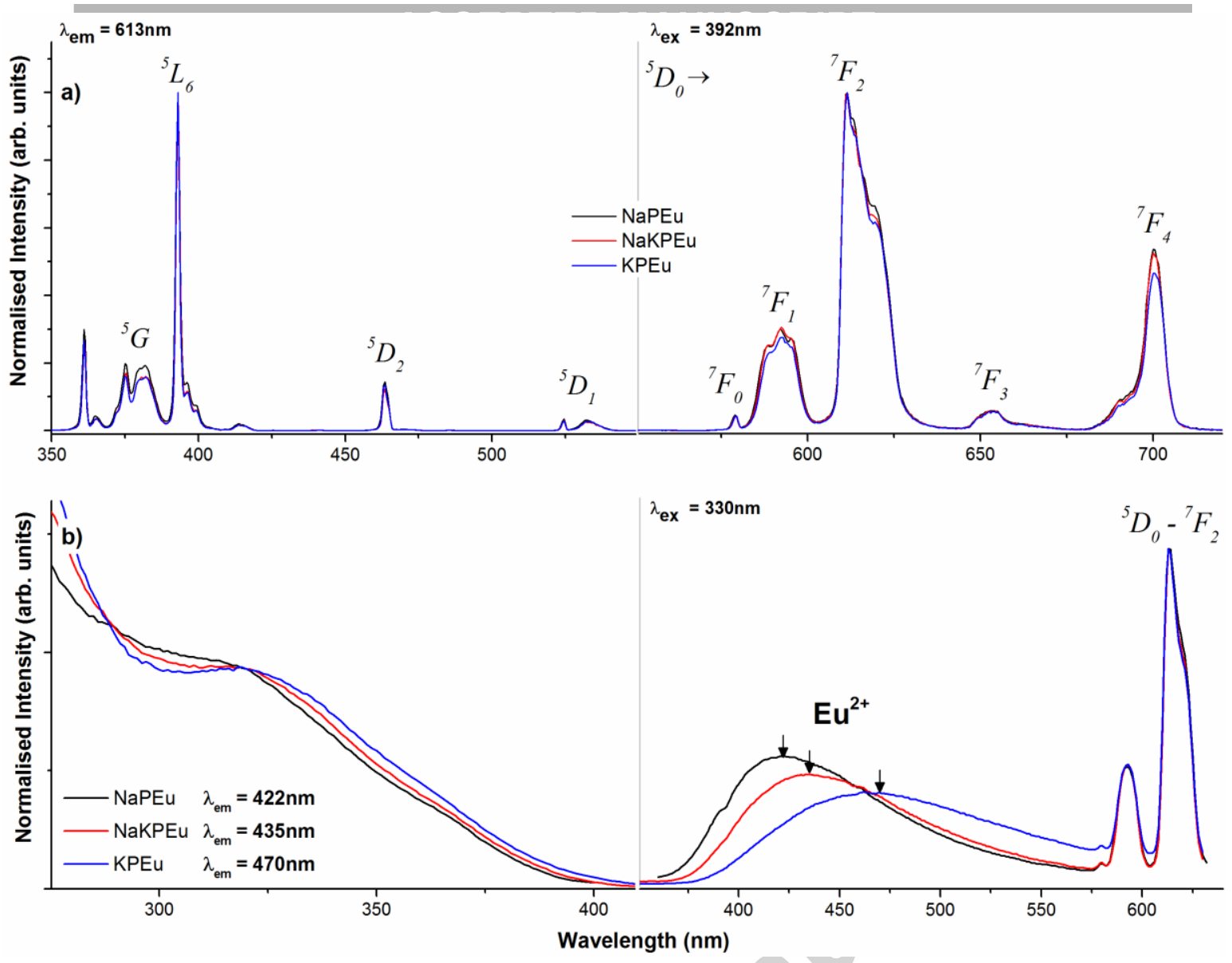

Figure 4 


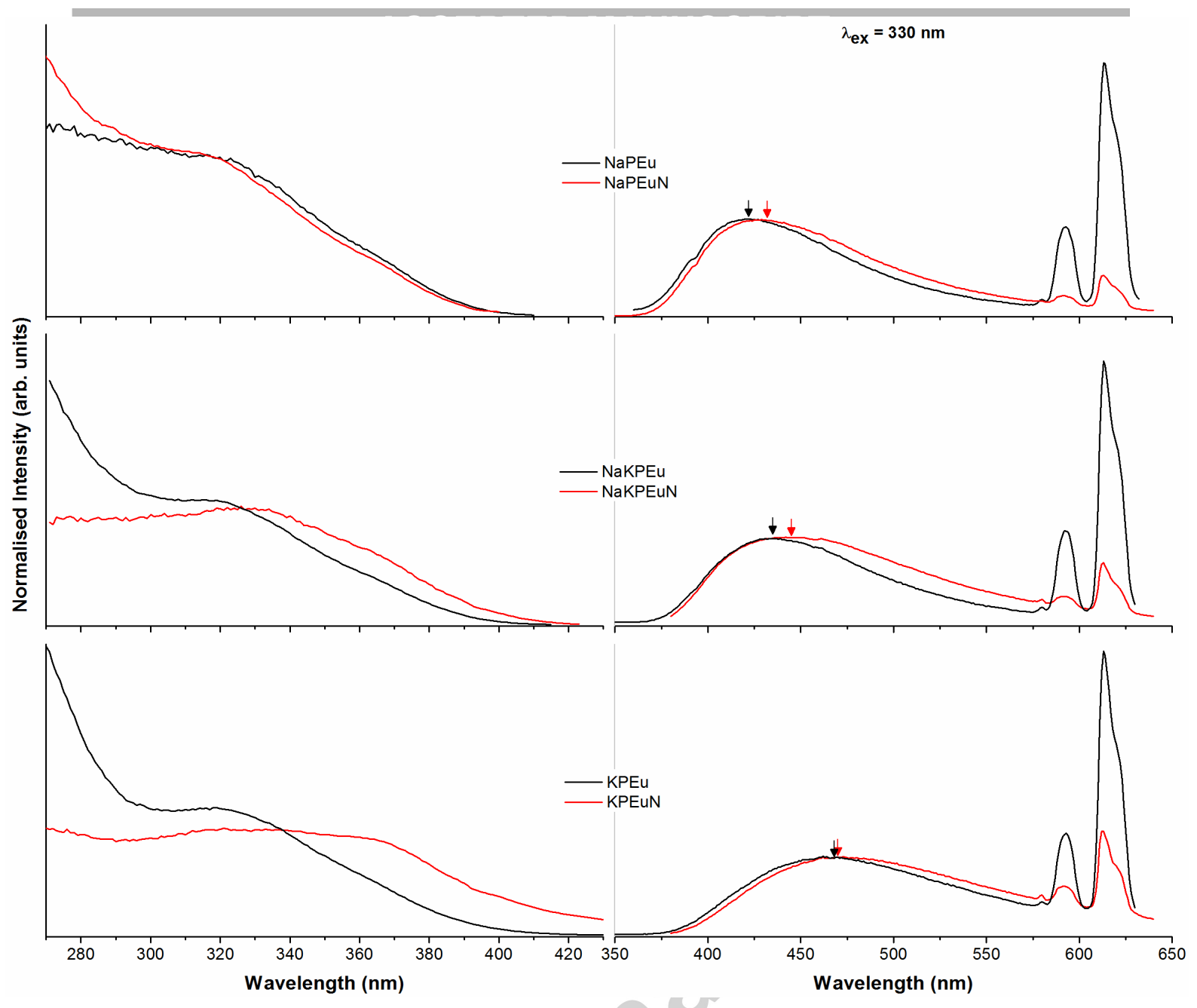

Figure 5: 


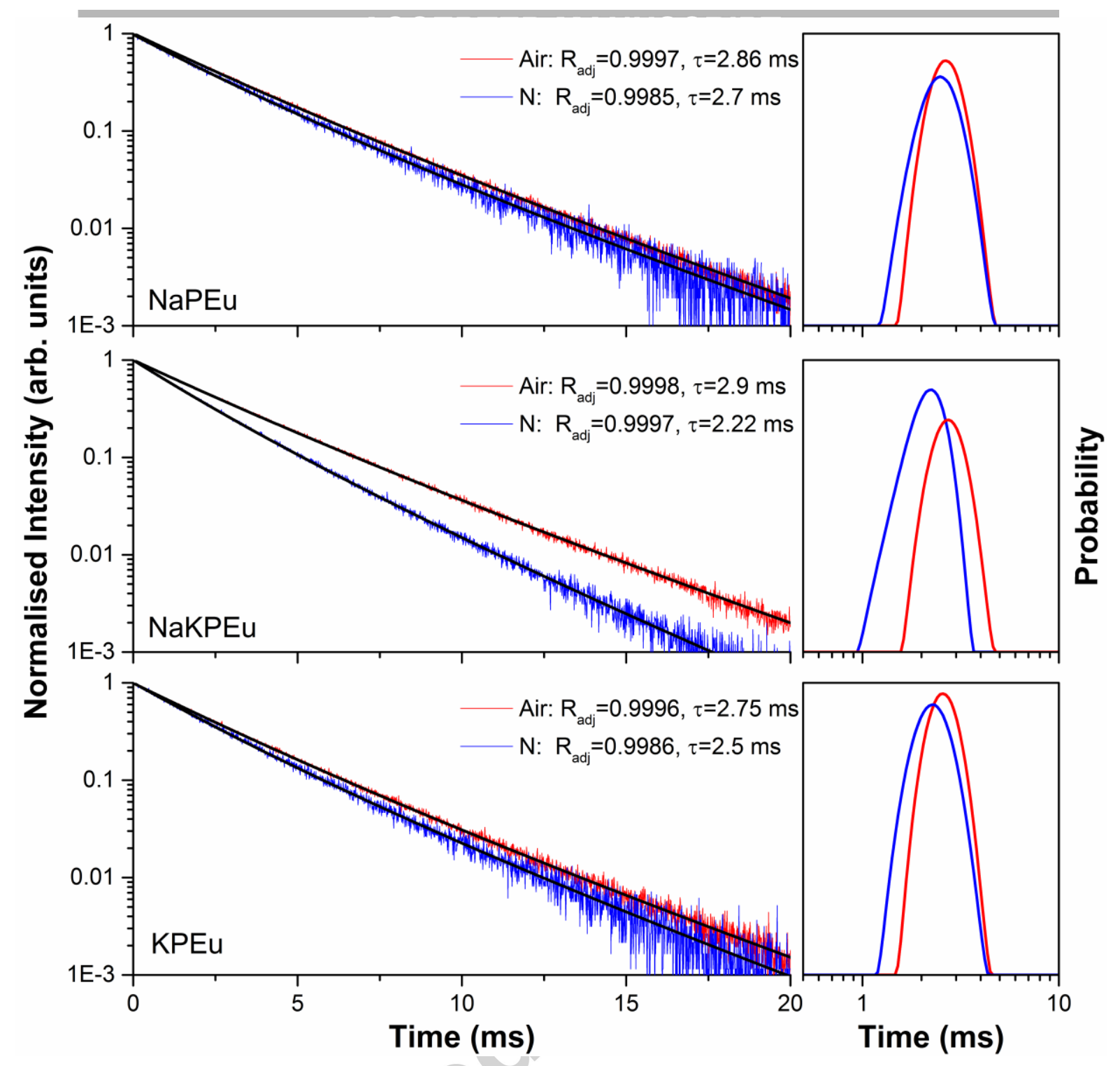

Figure 6 


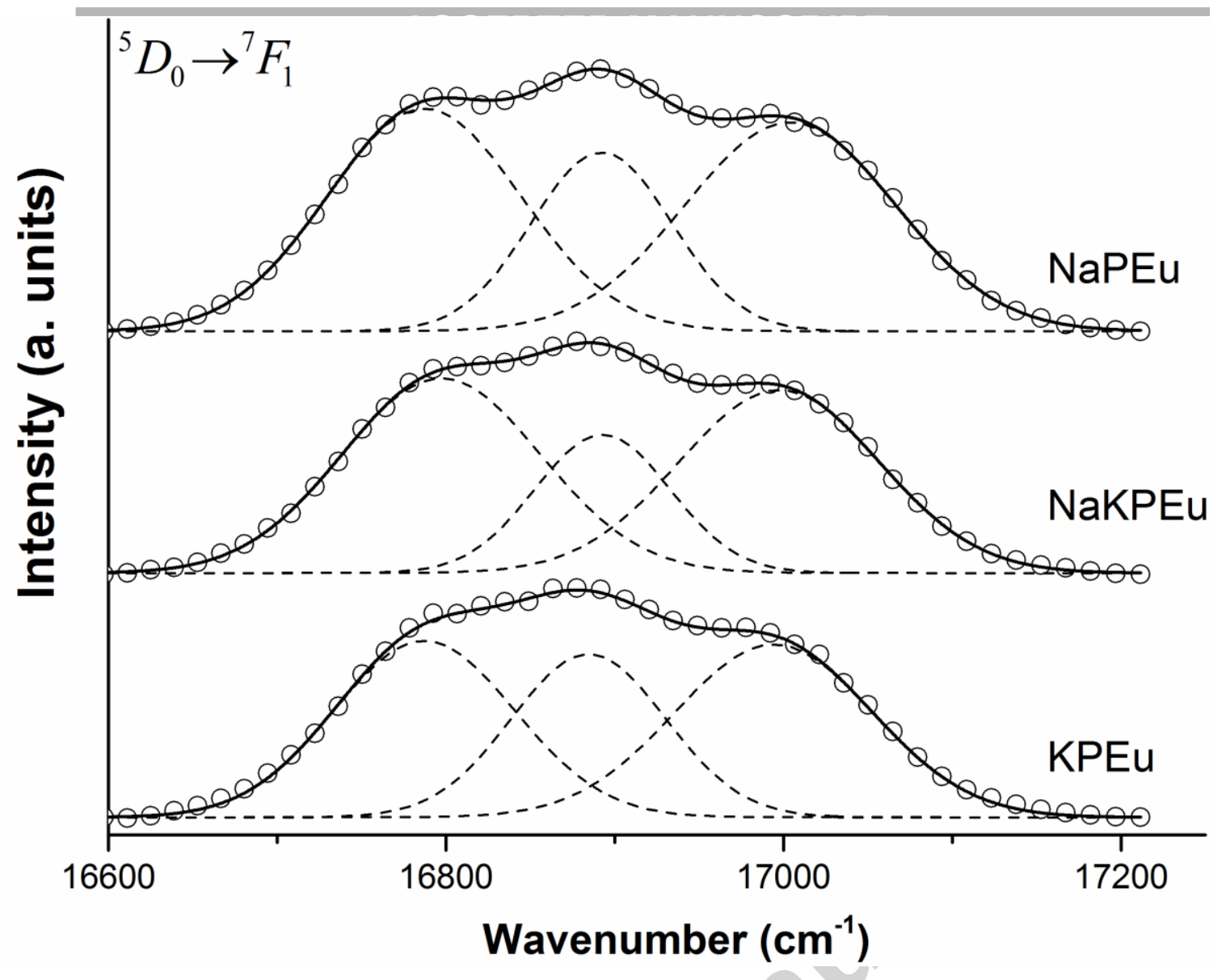

Figure 7

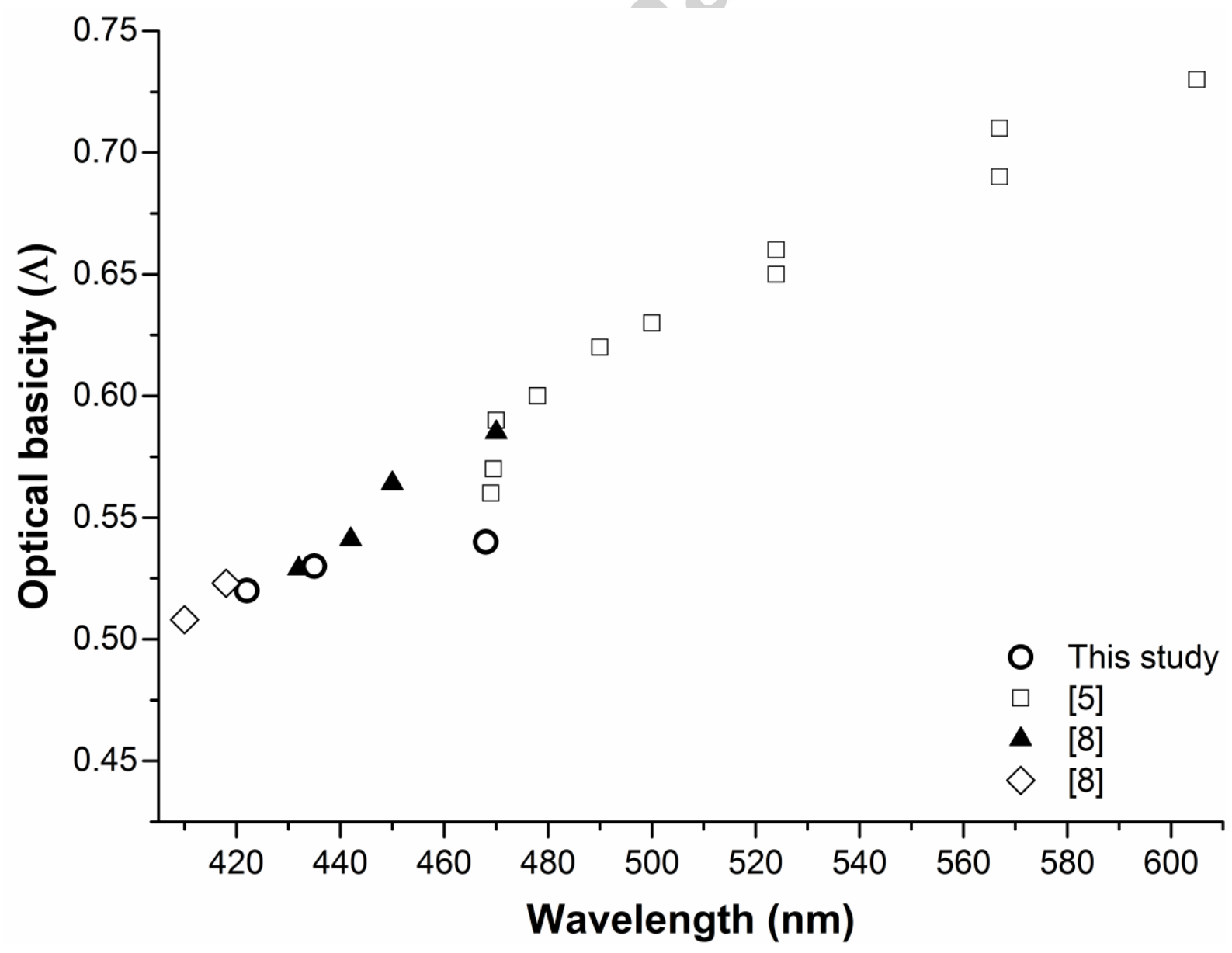


Figure 8

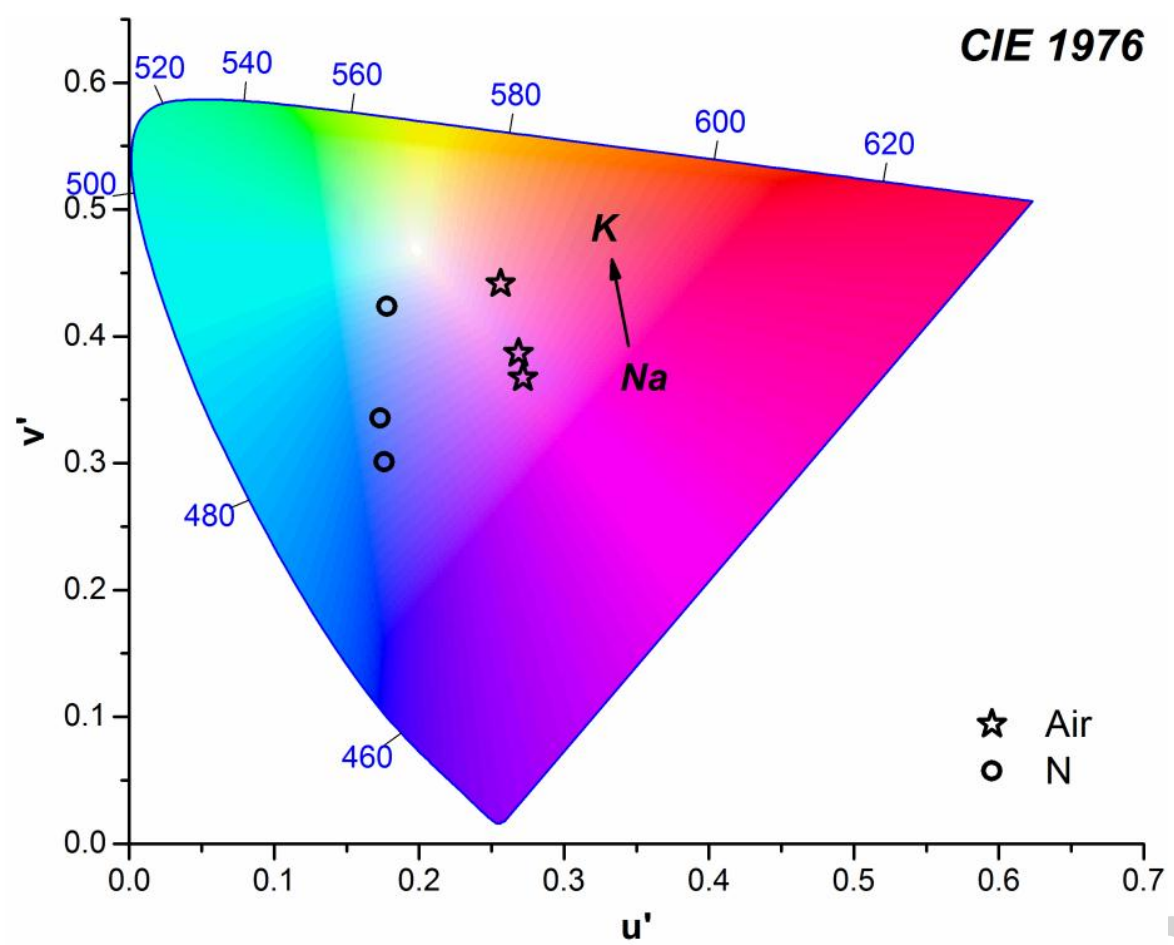

\section{Highlights:}

- Environmental friendly REE-phosphate glasses were studied

- The effect of substituting alkali elements on the glass structure and Eu thermal/optical properties was investigated

- We studied the effect of synthesis under $\mathrm{NH}_{3}$-flux on thermal/optical properties.

- We verified the chemistry controls on Eu emission tunability. 